\title{
1,4-Naphthoquinone Is a Potent Inhibitor of IRAK1 Kinases and the Production of Inflammatory Cytokines in THP-1 Differentiated Macrophages
}

Ismail Sami Mahmoud,* Ma'mon M. Hatmal, Duaa Abuarqoub, Ezaldeen Esawi, Hiba Zalloum, Suha Wehaibi, Hamdi Nsairat, and Walhan Alshaer*

Cite This: ACS Omega 2021, 6, 25299-25310

Read Online

ABSTRACT: Quinones are a class of cyclic organic compounds that are widely distributed in nature and have been shown to exhibit antiinflammatory, antioxidant, and anticancerous activities. However, the molecular mechanisms/signaling by which these molecules exert their effect are still not fully understood. In this study, a group of quinonederived compounds were examined for their potential inhibitory effect against human IRAK1 and IRAK4 kinases in vitro. We have identified five compounds: 1,4-naphthoquinone, emodin, shikonin, plumbagin, and menadione (vitamin $\mathrm{K} 3$ ) as active and selective inhibitors of human IRAK1 enzyme in vitro. The biochemical binding and molecular interactions between the active compounds and IRAK1's catalytic site were demonstrated in silico using structural-based docking and dynamic simulation analysis. Also, 1,4-naphthoquinone was found to effectively

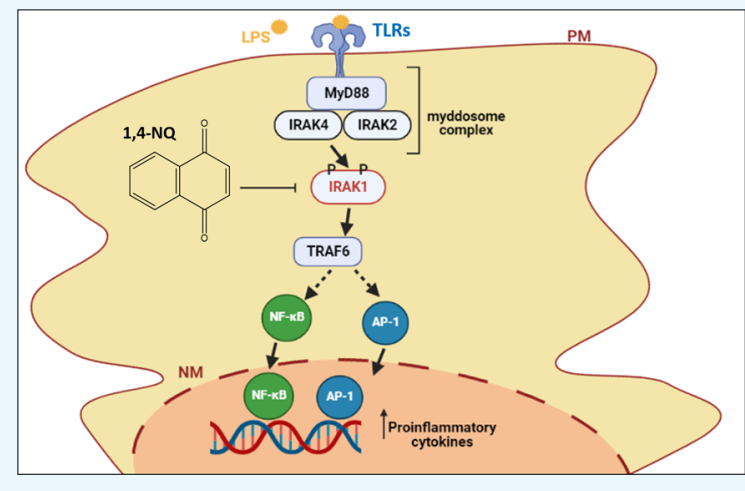
inhibit the growth of cancer cell lines overexpressing IRAK1. Furthermore, 1,4-naphthoquinone potently suppressed the production and secretion of key proinflammatory cytokine proteins IL-8, IL-1 $\beta$, IL-10, TNF- $\alpha$, and IL-6 in LPS-stimulated PMA-induced human THP-1 macrophages. In conclusion, 1,4-naphthoquinone is an effective inhibitor of IRAK1 kinases and their mediated inflammatory cytokines production in LPS-stimulated PMA-induced human THP-1 macrophages.

\section{INTRODUCTION}

Chronic inflammatory disorders and autoimmune diseases are serious health problems that require therapeutic interventions and affect the lives of millions of people worldwide. Interleukin1 receptor (IL1R) and Toll-like receptor (TLR) networks are critically involved in regulating the signaling of innate immune responses. ${ }^{1}$ TLR-4, a member of TLRs, can recognize pathogenassociated molecular pattern (PAMP) molecules, such as lipopolysaccharide (LPS), and activate key downstream signaling enzymes and transcription factors that mediate an immune response and inflammation, mainly by the induction of genes encoding key proinflammatory cytokines, such as IL-8, IL-6, IL12 , TNF- $\alpha$, INF- $\gamma$, and IL- $1 \beta$. $^{2}$

The interleukin-1 receptor-associated kinases (IRAKs) are key mediators of IL1R/TLRs signaling network in cells. ${ }^{3}$ There are four members of the mammalian IRAK family: IRAK1, IRAK2, IRAK3 (IRAKM), and IRAK4. Although IRAKs are categorized as serine/threonine kinases and all of them contain a kinase-like domain, only IRAK1 and IRAK4 exhibit kinase activity. ${ }^{4,5}$ IRAK4 plays a key role in mediating IL1R/TLR signaling and is rapidly recruited to the receptor-signaling complex upon IL1R/TLR activation. ${ }^{6}$ After binding to IL1R/ TLR, IRAK4 interacts with IRAK2 and MyD88 to form a large signaling complex, called the Myddosome. The assembly of this complex leads to the IRAK4-mediated recruitment and phosphorylation of IRAK $1 .{ }^{6}$ Phosphorylated IRAK1 could be released from the receptor complex and bind to the $\mathrm{E} 3$ ubiquitin ligase and TRAF6, which ultimately causes the induction of NF$\kappa \mathrm{B}$ as well as $\mathrm{AP}-1$ transcription factors, which results in the expression of a broad array of inflammatory cytokines and apoptosis-related proteins. ${ }^{6,7}$

Inhibition of IRAK1 and IRAK4 kinases has been shown to suppress inflammation. ${ }^{8,9}$ Indeed, IRAK4 kinase inhibition in human primary monocytes stimulated with TLR7/8 agonist (R848) blocks inflammatory cytokine RNA and protein production, including IL1, IL6, and TNF. ${ }^{10}$ Moreover, knocking down IRAK4 in microglial mouse cells significantly decreased IRAK4 expression and inhibited the downstream production of proinflammatory cytokines, which resulted in a significant reduction in intracerebral hemorrhage-induced brain inflamma-

Received: June 11, 2021

Accepted: September 3, 2021

Published: September 17, 2021 
<smiles>O=C1C=CC(=O)C=C1</smiles>

Benzoquinone<smiles>Oc1ccc(O)cc1</smiles>

Hydroquinone<smiles>CC1=CC(=O)C(C(C)C)=CC1=O</smiles>

Thymoquinone<smiles>O=C1C=CC(=O)c2ccccc21</smiles>

1,4-Naphthoquinone<smiles>O=C1C=CC(=O)c2c(O)cccc21</smiles>

Juglone<smiles>CC1=CC(=O)c2ccccc2C1=O</smiles>

Menadione (vit K3)<smiles>CC1=CC(=O)c2c(O)cccc2C1=O</smiles>

Plumbagin<smiles>Cc1cc(O)c2c(c1)C(=O)c1cc(O)cc(O)c1C2=O</smiles>

Emodin<smiles>CC(C)=CC[C@@H](O)C1=CC(=O)c2c(O)ccc(O)c2C1=O</smiles>

Shikonin<smiles>CC(C)=CCC1=C(O)C(=O)c2ccccc2C1=O</smiles>

Lapachol<smiles>CC1=C(C/C=C(\C)CCC[C@H](C)CCC[C@H](C)CCCC(C)C)C(=O)c2ccccc2C1=O</smiles><smiles>CC(C)=CCC1=C(C)C(=O)c2ccccc2C1=O</smiles><smiles>CC=C(C)CCC=C(C)CCC=C(C)C</smiles><smiles>CCCN1CCOCC1</smiles>

Menaquinone (vit K2)

Figure 1. Chemical structures of the quinone-derived compounds used in this study.

tion in mice. ${ }^{11}$ On the other hand, significant upregulated IRAK1 expression has been reported in obese human adipose tissues, and its expression levels were associated with local and circulatory inflammatory signatures. ${ }^{12}$ Singhb and Li demonstrated that deletion of IRAK1 gene in mice may protect from LPS-induced oxidative tissue damage and showed that LPS caused significantly less damage to liver and kidney tissues in IRAK1-deficient mice compared to wild-type mice. ${ }^{13}$ In another study, mice deficient in IRAK1 showed a decrease in the production of cytokines and delayed inflammatory response following polymicrobial sepsis, where the sepsis-induced mortality was markedly lower in IRAK1-deficient mice compared to wild type. ${ }^{14}$ This clearly indicates that the lack of IRAK1-mediated signaling downregulates the early phase of cytokine cascade during inflammation. Collectively, it is clear from the previously conducted studies that IRAK1 and IRAK4 play a critical role in mediating inflammatory response, and inhibition of these kinases is a promising strategy to reduce inflammatory disorders.

Quinones are a class of redox-active cyclic organic compounds that contain two carbonyl groups, either adjacent or separated, in a six-membered ring structure. ${ }^{15}$ Quinone-derived compounds, either natural or synthetic, will have a characteristic common basic structural pattern: a single aromatic nucleus (benzoquinones) or polycyclic aromatic system, such as naphthoquinones and anthraquinones. ${ }^{16}$ Quinones have two main properties that are essential for understanding their biological effects. First, quinones are highly redox-active molecules that can undergo oxido-reduction reactions leading to the formation of reactive oxidative species (ROS), and second, many of them can undergo nucleophilic attack due to their electrophilic character, which ultimately may enhance their binding to proteins, DNA, and other molecules. ${ }^{16}$ Quinones are widely distributed in nature and can be found in several living organisms including plants, bacteria, fungi, and some animals where they play an important role in biological processes such as photosynthesis, anti-oxidation, and aerobic respiration. ${ }^{16}$ Also, several quinone compounds have been shown to exhibit antiinflammatory and anticancerous activity, including thymoquinone (2-isopropyl-5-methyl-1,4-benzoquinone), ${ }^{17,18}$ 1,4-naphthoquinone, ${ }^{19,20}$ emodin (1,3,8- trihydroxy-6-methylanthraquinone), ${ }^{21,22}$ lapachol (2-hydroxy-3-(3-methyl-2-butenyl)-1,4naphthoquinone), ${ }^{23,24}$ plumbagin (5-hydroxy-2-methyl-1,4naphthoquinone), ${ }^{25,26}$ juglone (5-hydroxy-1,4-naphthoquinone), ${ }^{27}$ shikonin (5,8-dihydroxy-2-(1-hydroxy-4-methyl-3pentenyl)-1,4-naphthoquinone), ${ }^{28}$ and vitamin $\mathrm{K}^{29,30}$

In this study, a group of quinone-derived compounds, with known anti-inflammatory activity, including thymoquinone, 1,4naphthoquinone, benzoquinone, hydroquinone, emodin, lapachol, plumbagin, juglone, shikonin, phylloquinone (vitamin $\mathrm{K} 1$ ), menaquinone (vitamin K2), and menadione (vitamin K3) (Figure 1), were evaluated for their ability to inhibit the kinase 
activity of IRAK1 and IRAK4 in vitro. The compounds, which exerted prominent anti-kinase activity in vitro, were then analyzed using in silico methods to define the binding interactions between these compounds and the enzyme's catalytic binding site. For further investigations, the compound of highest anti-kinase activity was then selected and examined for its ability to inhibit growth of cancer cell lines in vitro as well as the inflammatory response in LPS-stimulated PMA-induced human THP-1 macrophages.

\section{RESULTS AND DISCUSSION}

Measuring the Inhibitory Effect of Quinone Compounds on IRAK1 and IRAK4 Enzymes In Vitro. The quinone compounds were tested against human IRAK1 and IRAK4 enzymes using fluorescence resonance energy transfer (FRET)-based Adapta and ZLYTE Kinase assays. For initial screening, $10 \mu \mathrm{M}$ of each quinone compound was used in the assays. Only five compounds, 1,4-naphthoquinone, emodin, shikonin, plumbagin, and vitamin K3, showed a significant kinase inhibition of IRAK1 ( $>20 \%$ inhibition of IRAK1 kinase activity) (Table 1). 1,4-Naphthoquinone showed the highest

Table 1. Inhibitory Effect of Quinone-Derived Compounds at a Concentration of $10 \mu \mathrm{m}$ on IRAK1 and IRAK4 Enzyme Activity Using Kinase Assays

\begin{tabular}{lrrrr}
\multicolumn{1}{c}{ compounds } & \multicolumn{4}{c}{ \% of kinase inhibition } \\
\cline { 3 - 6 } \cline { 3 - 6 } 1,4-benzoquinone & 20 & 0 & 0 & 1 \\
thymoquinone & 5 & 4 & 0 & 1 \\
hydroquinone & 15 & 7 & 4 & 1 \\
1,4-naphthoquinone & $91^{a}$ & 1 & 10 & 2 \\
emodin & $74^{a}$ & 6 & 9 & 1 \\
juglone & 0 & 0 & 0 & 0 \\
lapachol & 8 & 11 & 3 & 1 \\
shikonin & $79^{a}$ & 2 & 0 & 0 \\
plumbagin & $54^{a}$ & 1 & 0 & 0 \\
phylloquinone (Vitamin K1) & 14 & 4 & 9 & 1 \\
menaquinone (Vitamin K2) & 18 & 5 & 4 & 1 \\
menadione (Vitamin K3) & $28^{a}$ & 1 & 0 & 0 \\
IRAK-1/4 Inhibitor & $100^{a}$ & 0 & $94^{a}$ & 1
\end{tabular}

${ }^{a}$ Indicates inhibitory efficacy above $20 \%$ at $10 \mu \mathrm{M}$. SD, standard deviation.

efficacy in the inhibition of IRAK1, followed by shikonin, emodin, plumbagin, and vitamin K3. Paradoxically, thymoquinone, which has recently been shown to directly suppress IRAK1 activity, ${ }^{17}$ did not demonstrate anti-IRAK1 activity in our assay. This discrepancy in thymoquinone activity between the studies could be mainly due to a different concentration of thymoquinone that has been used. Hossen et al. have used an approximately 1 -fold higher concentration of thymoquinone in their kinase assays $(25 \mu \mathrm{M})$. In addition, they used different kinase assays to evaluate thymoquinone activity against IRAK1 enzyme, which could be another factor of variation. ${ }^{17}$ On the other hand, all quinone compounds tested in this study were not active against IRAK4 at $10 \mu \mathrm{M}(<20 \%$ inhibition of IRAK4 kinase activity) (Table 1 ). The IRAK-1/4 inhibitor was used as a control inhibitor in the experiments and demonstrated high activity in the inhibition of IRAK1 and IRAK4 (100\% inhibition at $10 \mu \mathrm{M})$. For further investigations, the active compounds against IRAK1 enzyme were selected and the $\mathrm{IC}_{50}$ value of each one was determined (Figure 2A). Notably, 1,4-naphthoquinone compound showed the highest activity (lowest $\mathrm{IC}_{50}$ ) among tested quinones $(914 \mathrm{nM})$, followed by emodin (1426 nM), shikonin $(4528 \mathrm{nM})$, plumbagin $(6328 \mathrm{nM})$, and vitamin $\mathrm{K} 3$ $(45088 \mathrm{nM})$ (Figure 2B). However, the $\mathrm{IC}_{50}$ value of the control IRAK-1/4 inhibitor against IRAK1 enzyme was $21 \mathrm{nM}$.

IRAK1 inhibitors are chemical agents that selectively inhibit IRAK1 and block its subsequent activation of downstream cascade of mediators and transcription factors. In fact, there are only a few selective inhibitors of IRAK1 that have been developed so far. For example, pacritinib is a known JAK2/FLT3 inhibitor; surprisingly, it was also found to inhibit IRAK1 with moderate selectivity versus IRAK4 $\left(\mathrm{IC}_{50}: 6 \mathrm{nM}\right.$ vs $177 \mathrm{nM}$, respectively). ${ }^{9}$ Just recently, a new small molecule JH-X-119-01 has been reported to be an irreversible inhibitor of IRAK1 by forming a covalent bond at Cys 302 residue of IRAK1 enzyme $\left(\mathrm{IC}_{50}\right.$ of $9.3 \mathrm{nM}$ and $>10 \mu \mathrm{M}$ against IRAK1 and IRAK4, respectively). ${ }^{31}$ In this study, we have identified five natural quinone compounds, 1,4-naphthoquinone, emodin, shikonin, plumbagin, and vitamin $\mathrm{K} 3$, to selectively inhibit the IRAK1 enzyme. Among these compounds, 1,4-naphthoquinone was found to inhibit IRAK1 in a high efficiency.

The identified five quinones in this study seem to be more selective to IRAK1, whereas IRAK1/4 dual inhibitors hit both IRAK1 and IRAK4 enzymes. Usually, IRAK1/4 dual inhibitors possess two different biological activities, which could be an advantage of the IRAK dual inhibitor by maximizing the pharmacological efficacy, but when the defect is only in IRAK1 kinase and a selective targeting is required, that could provoke unwanted side effects and increased toxicity because direct inhibition of IRAK4 and other IRAK4-dependent downstream signaling cascades could lead to dysregulation of critical physiological functions in humans, such as the removal of developing autoreactive $\mathrm{B}$ cells and the induction of innate immune responses against bacterial and viral infections. ${ }^{32,33}$ Therefore, selectively targeting IRAK1 with high efficacy and low side toxicity may provide an alternative safer approach of targeting IRAK1-mediated inflammation.

Docking and Binding Interactions of Quinones and IRAK-1/4 Inhibitor with IRAK1's Catalytic Site. To understand how quinones could inhibit IRAK1 enzymatic activity, the five active quinone compounds, 1,4-napthoquinone, shikonin, emodin, blumbagin, and vitamin $\mathrm{K} 3$, in addition to the IRAK-1/4 inhibitor, were successfully docked into the catalytic site of IRAK1 (Figure 3A-F). The docking models show the proposed binding interactions anchoring the five investigated docked quinones compounds and the IRAK-1/4 inhibitor within the IRAK1's catalytic site (Figure 4A-F). Clearly, the docked compounds bind into IRAK1's catalytic site mainly via hydrogen bonding, hydrophobic interaction, and $\pi$-stacking. The binding of IRAK-1/4 inhibitor is mediated by one $\mathrm{H}$-bond that connects its carbonyl oxygen atom to the sp2-hybridized nitrogen of LEU291 of the hinge region, in addition to cation $-\pi$ and anion $-\pi$ electrostatic interactions mediated by positively charged nitrogen $(\mathrm{N}+)$ and negatively charged oxygen $(\mathrm{O}-)$ atoms of its nitro group with the phenolic side chain (electronrich $\pi$ system) of TYR288, respectively (Figure 4A), and also $\pi-\pi$ stacking interactions involving its nitrobenzene and the phenolic side chain of TYR288 (Figure 4A). In addition to multiple hydrophobic interactions mediated by ALA237, LEU347, ILE218, and VAL226. Moreover, weak nonconventional carbon-hydrogen bonds involving SER344 and ILE218 were also found to mediate the binding (Figure 4A). 
(A)
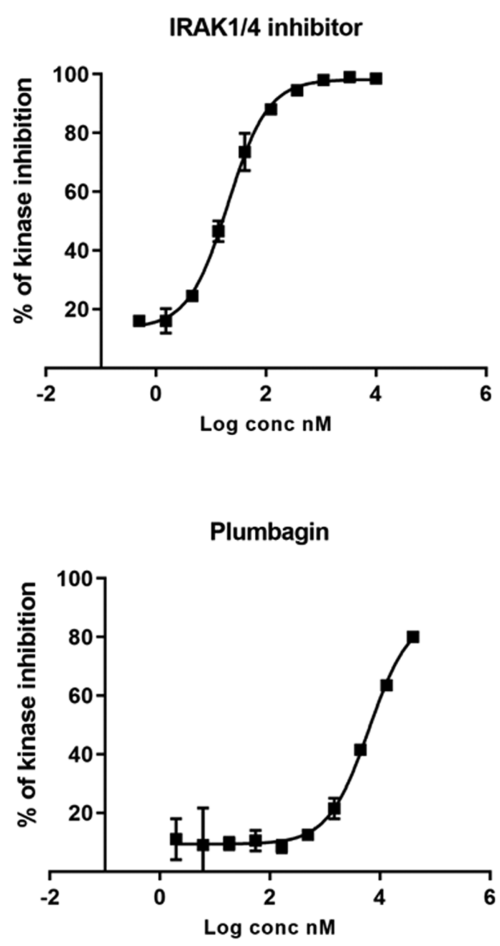

1,4-naphthoquinone

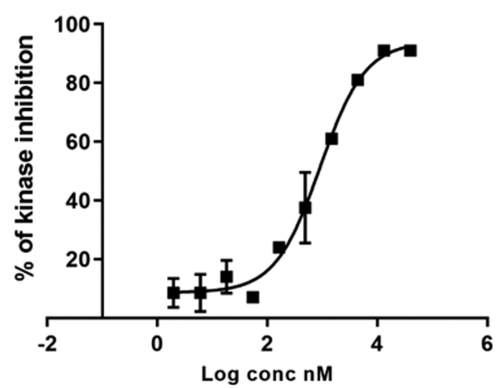

Shikonin

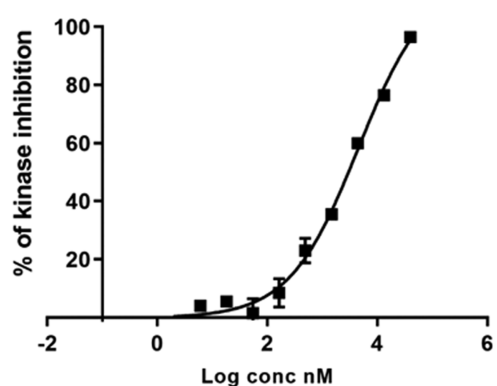

Emodin

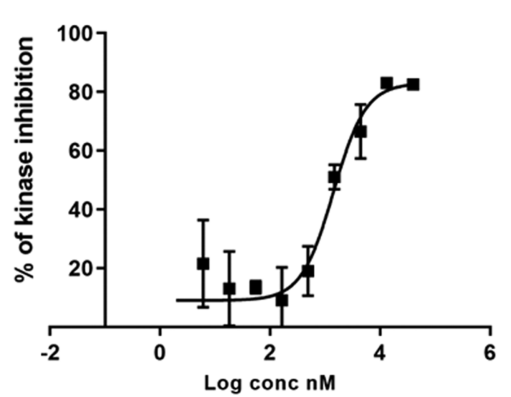

Vit K3

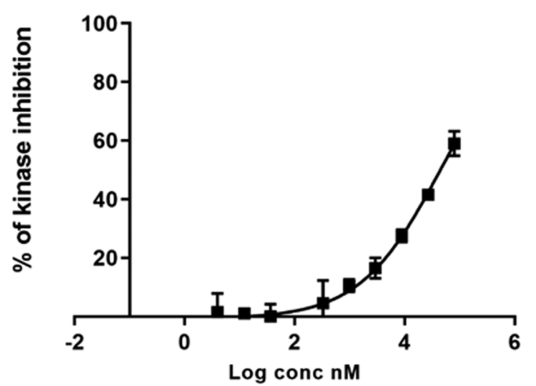

(B)

\begin{tabular}{cc}
\hline Compounds & IC $_{50}$ (nM) \\
\hline 1/4 IRAK1 inhibitor & 21 \\
1,4 naphthoquinone & 914 \\
\hline Emodin & 1426 \\
\hline Shikonin & 4528 \\
\hline Plumbagin & 6328 \\
\hline Vitamin K3 & 45088 \\
\hline
\end{tabular}

Figure 2. Determination of $\mathrm{IC}_{50}$ values of active quinone-derived compounds on IRAK1 enzyme using kinase assays. (A) Five compounds: 1,4naphthoquinone, emodin, shikonin, plumbagin, and vitamin K3, in addition to the control inhibitor (IRAK-1/4 inhibitor) were serially diluted and tested against human IRAK1 enzymes using fluorescence resonance energy transfer-based kinase assay (Adapta). Data are expressed as mean \pm SD. (B) $\mathrm{IC}_{50}$ value of each compound was calculated using the nonlinear regression (variable slope, four parameters) of the log concentration as inhibition percentage values using GraphPad Prism 9.0.

For quinone docking, 1,4-napthoquinone and vitamin $\mathrm{K} 3$ showed similar docked poses that involve one hydrogen-bond interaction connecting their carbonyl oxygen atom with the sp2hybridized nitrogen of LEU291 (Figure 4B,D), in addition to weak nonconventional carbon-hydrogen bonds involving the PHE290 residue (Figure 4B,D). In fact, both compounds have very close chemical structures, although there is an extra methyl group in vitamin $\mathrm{K} 3$. We believe that the presence of a methyl group in the structure of vitamin $\mathrm{K} 3$ will add more steric hindrance to vitamin $\mathrm{K} 3$ and might decrease the entropy, which makes Gibbs free energy less favorable. Moreover, this methyl group may impose certain binding modes different from those of 1,4-naphthoquinone. ${ }^{34}$ That could explain why 1,4-naphthoquinone has much more affinity to IRAK1 enzyme than vitamin $\mathrm{K} 3\left(\mathrm{IC}_{50}\right.$ : $914 \mathrm{nM}$ vs $45088 \mathrm{nM}$, respectively). Blumbagin interaction involves two hydrogen bonds: one connects its carbonyl oxygen atom to the sp2-hybridized nitrogen of LEU291, and the other is mediated by its hydroxyl group, which binds to the carbonyl oxygen of LEU291 (Figure 4E). Also, a nonconventional carbon-hydrogen bond involving PHE290 was detected (Figure 4E). Shikonin binding is mediated mainly by forming a hydrogen bond between its hydroxyl group and the carbonyl oxygen atom of ILE218, in addition to $\pi-\pi$ stacking interaction that is mediated by the phenolic side chain of TYR288 (Figure 4C). Emodin forms one hydrogen bond between its hydroxyl group and the carbonyl oxygen of $\alpha$ carbon of GLU220, and a weak carbon-hydrogen bond mediated by GLY294 (Figure 4F). Remarkably, the docked poses of the five quinones share common putative hydrophobic interactions $(\pi$-alkyl) connecting their benzene rings with the isobutyl and methyl groups of LEU347 and ALA237, respectively (Figure 4A-F). Notably, the presence of noncovalent interactions between the docked quinone compounds and the IRAK1's binding site may indicate reversible binding. ${ }^{35}$ However, binding kinetics between IRAK1 enzyme and quinone compounds should be tested experimentally in the future to confirm the type of binding.

Overall, the sp2-hybridized nitrogen of LEU291 within IRAK1's catalytic site seems to play a key role in mediating molecular binding by forming hydrogen bonds with the carbonyl oxygen atom of the quinones and IRAK-1/4 inhibitor. Also, hydrophobic interactions mediated by LEU347, ALA237, 
A<smiles>CCCCCCCC</smiles>
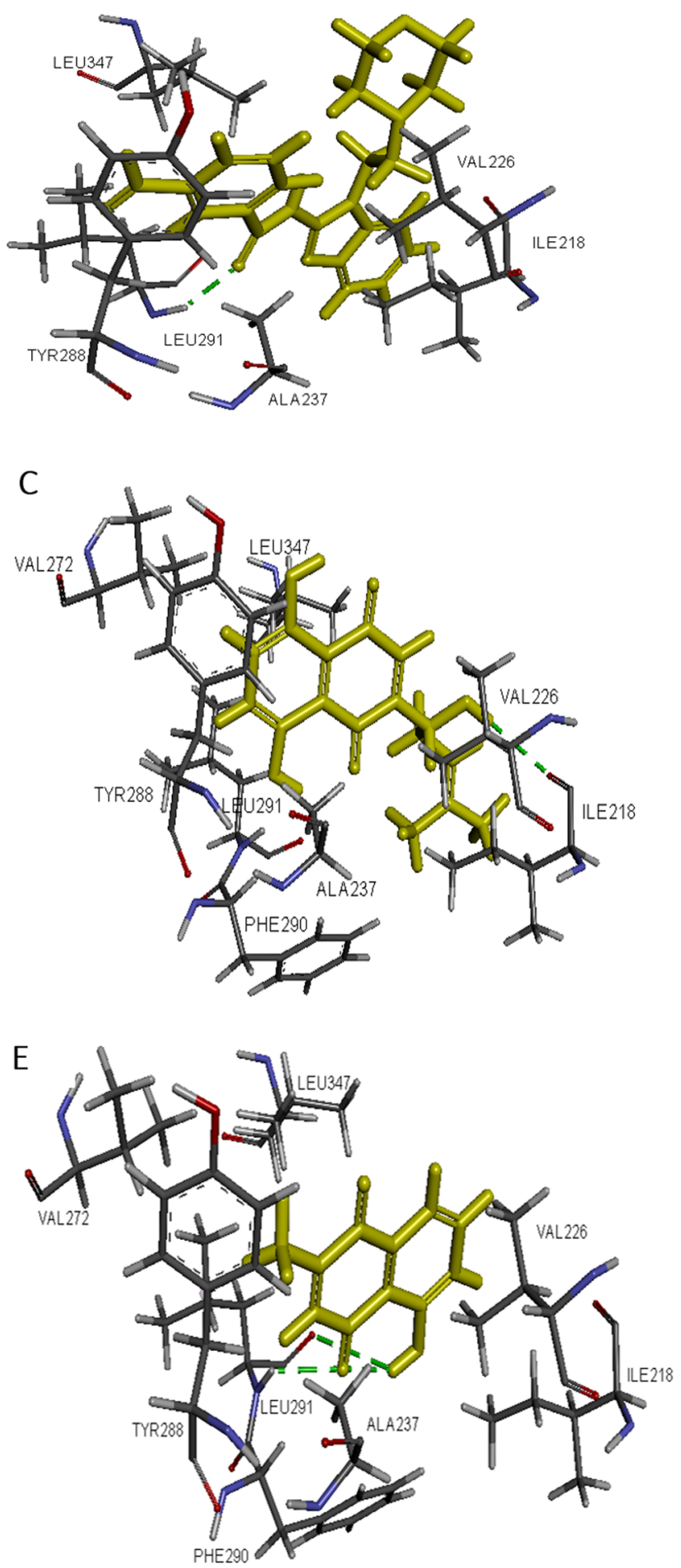

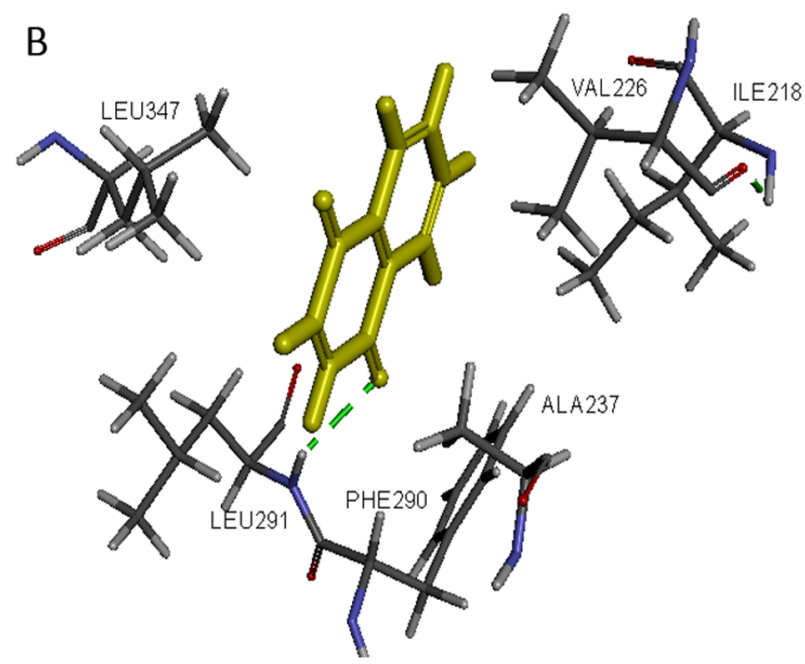

D

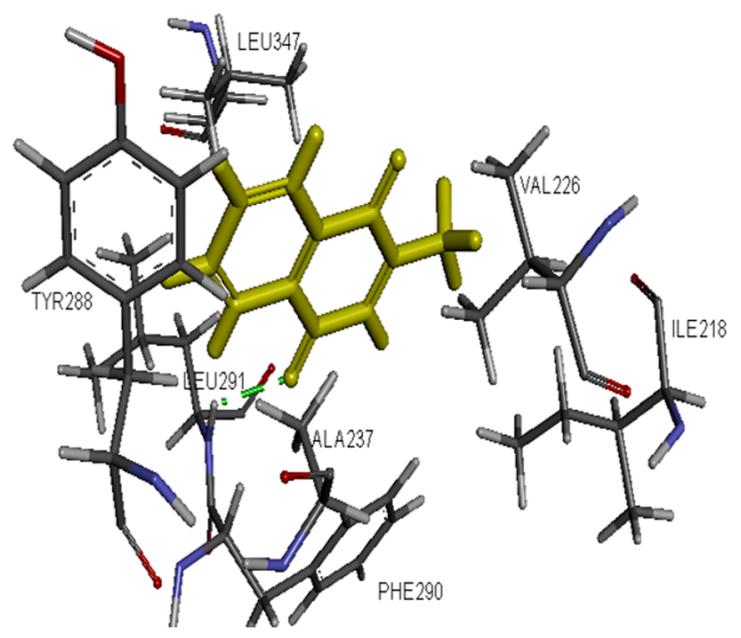

F

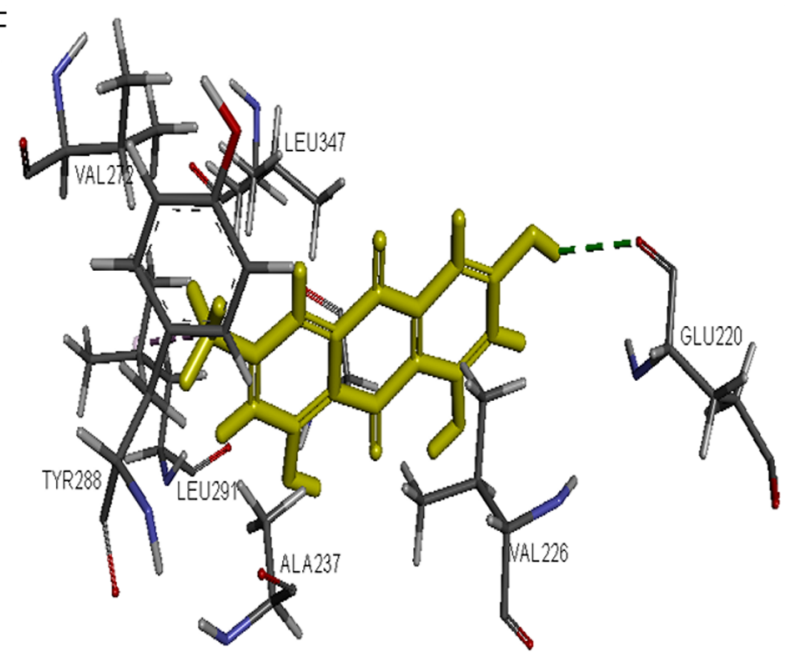

Figure 3. Docking analysis of quinones and IRAK-1/4 inhibitor with IRAK1's catalytic site. The docking analysis was conducted using the collected set of compounds (yellow) into the proposed binding pocket of the X-ray crystallographic structure of human IRAK1 (PDB ID: 6BFN, resolution: 2.26 $\AA$ ). The docking was carried out using the docking engine CDOCKER. (A) IRAK-1/4 inhibitor, (B) 1,4-napthoquinone, (C) shikonin, (D) vitamin $\mathrm{K} 3$, (E) plumbagin, and $(\mathrm{F})$ emodin. Hydrogen bonds are depicted by the green dotted line.

VAL226, and TYR288 are important for the binding. Interestingly, these results are consistent with the previous work described the X-ray crystal structure of the human IRAK1 kinase domain in complex with a small-molecule inhibitor JH-I-
25 , which demonstrated that the inhibitor JH-I-25 stabilized in the catalytic site by forming a single hydrogen bond with the hinge region residue LEU291 and a $\pi-\pi$ stacking interaction with TYR288. ${ }^{36}$ 
A

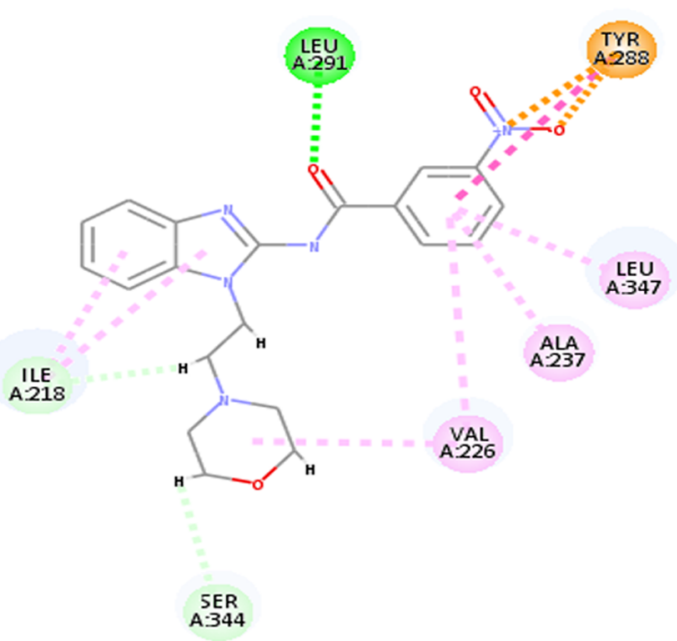

C

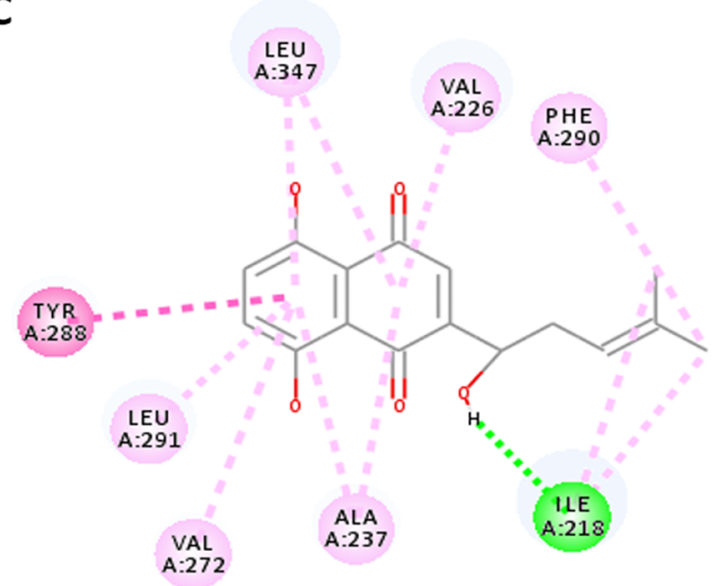

$\mathbf{E}$

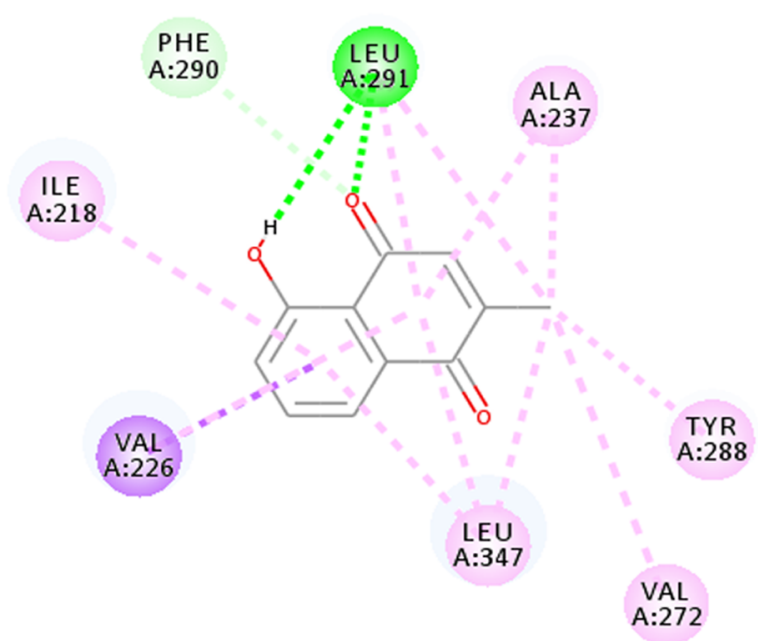

B

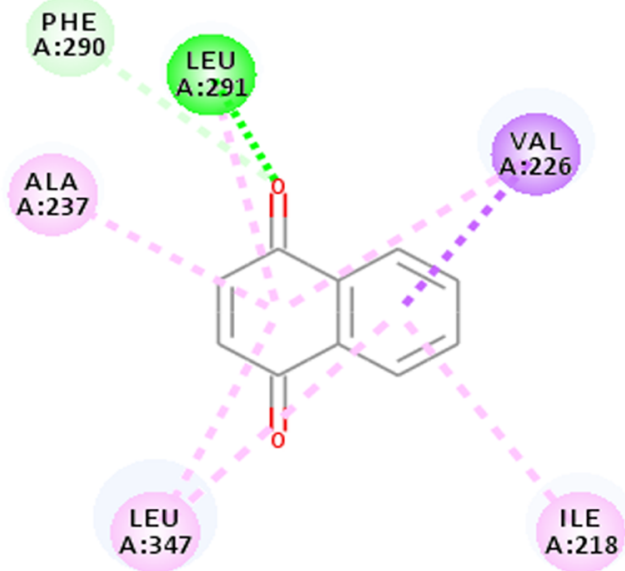

D

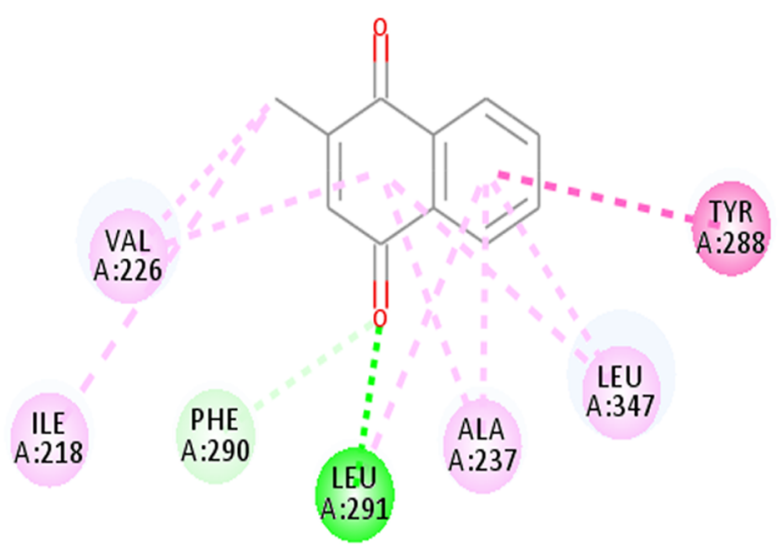

$\mathbf{F}$

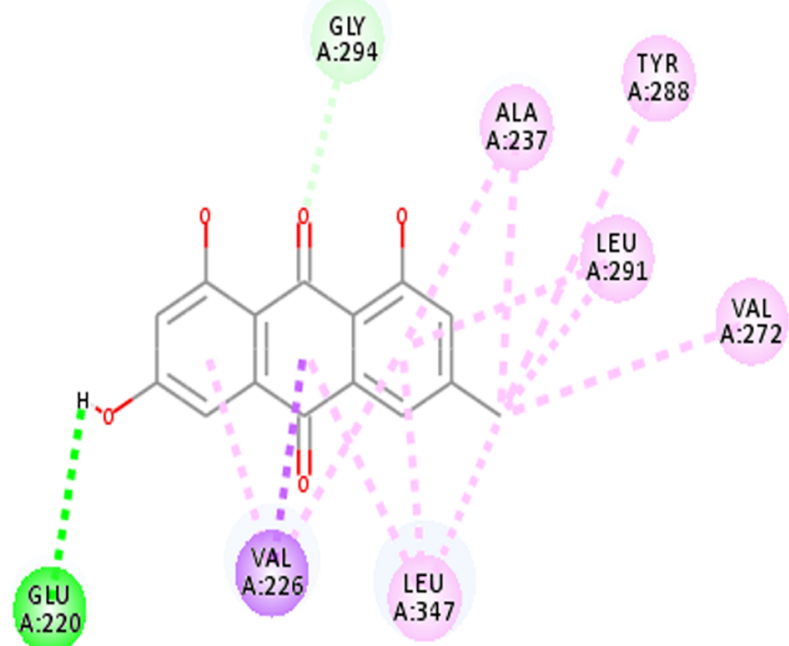

Figure 4. Molecular interactions mediating binding of quinones and IRAK-1/4 inhibitor with IRAK1's catalytic site. Discovery Studio Visualizer V20.1.0.19295 (Dassault Systems BIOVIA) was used to generate a two-dimensional (2D) interaction map that shows interactions between docked quinone compounds and IRAK1 catalytic binding site. (A) IRAK-1/4 inhibitor, (B) 1,4-napthoquinone, (C) shikonin, (D) vitamin K3, (E) plumbagin, and (F) emodin. Molecular interactions are depicted by colored dotted lines. Conventional hydrogen bond (green), carbon-hydrogen bond (blue), pi-cation and pi-anion bonds (orange), pi-pi stacking (pale red), alkyl and pi-alkyl (pink), and pi-sigma (purple).

Cytotoxic Effect of 1,4-Naphthoquinone on the Growth of Cancer Cells Expressing IRAK1 in Various
Levels. The 1,4-napthoquinone compound, the most active anti-IRAK1 quinone identified in this study, was then selected 

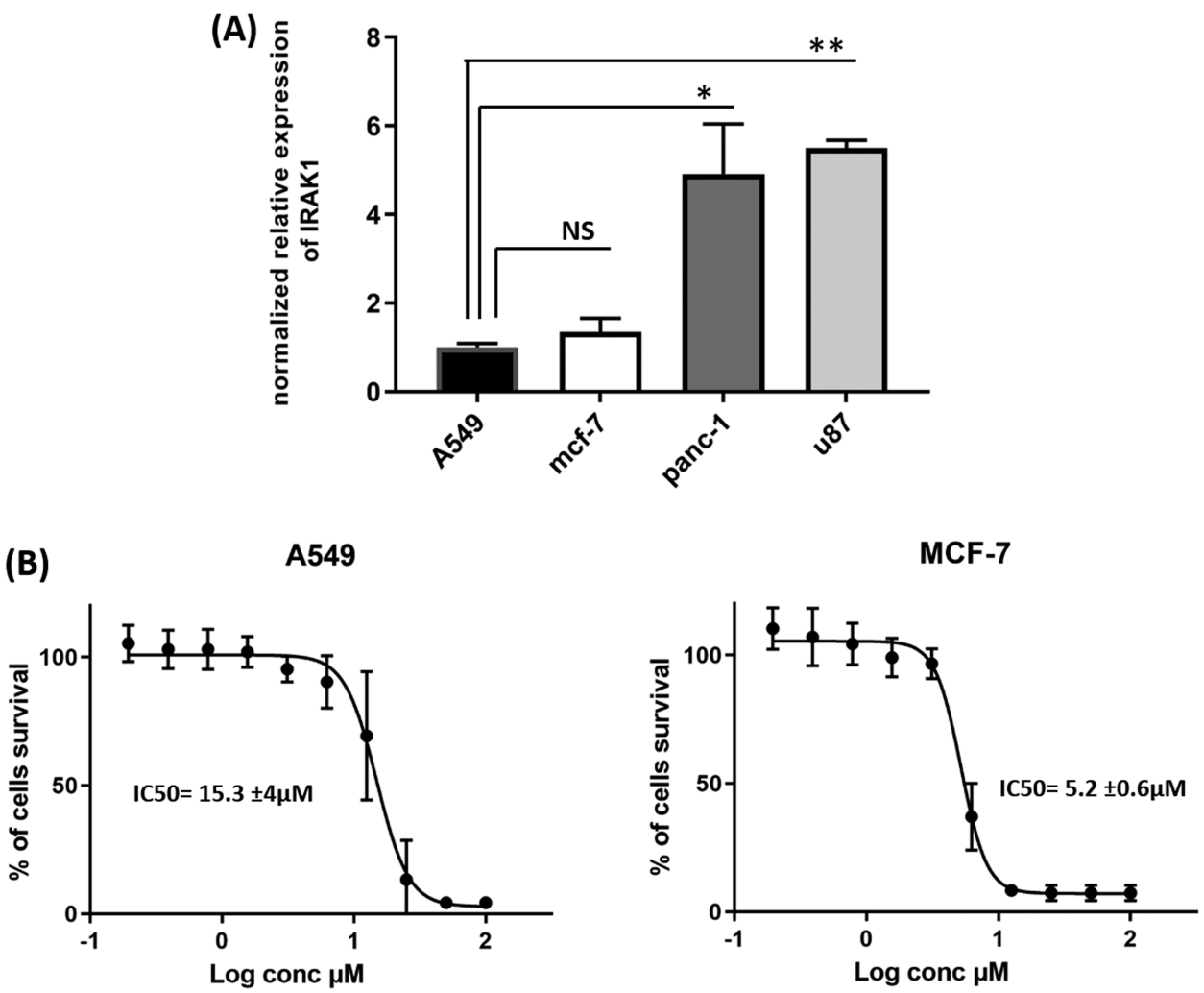

PANC-1

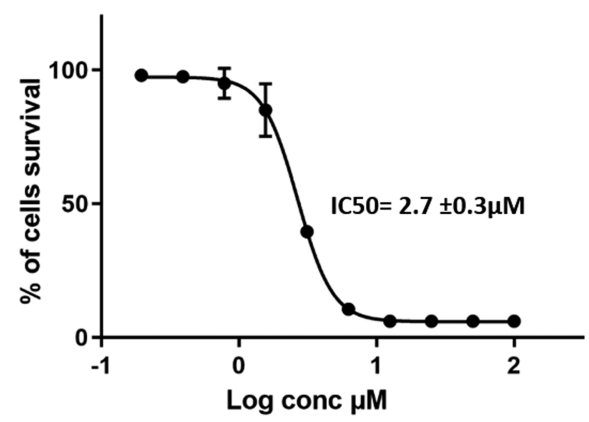

U87

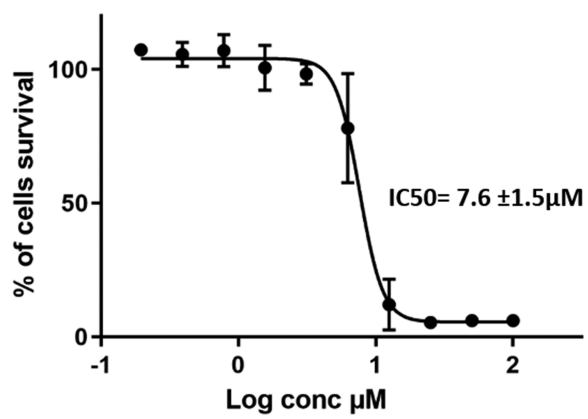

Figure 5. Relative RNA expression of IRAK1 gene and cell cytotoxicity of 1,4-naphthoquinone on cancer cell lines. (A) RNA was isolated from indicated cell lines and quantified using QPCR technique. Expression of IRAK1 gene was normalized against internal housekeeping gene 18S-rRNA. (B) MTT cytotoxicity assays show survival percentage of cells after treatment with different log concentrations of 1,4-naphthoquinone and incubated for $72 \mathrm{~h}$. Data expressed as mean \pm SD. $P$-value was calculated using $t$-test. $* p<0.05$. $* * p 0.01$. NS (not significant).

and tested on cancer cells. The cancer cell lines MCF-7, U87, PANC-1, and A549 cells have been found to express IRAK1 RNA in various levels (Figure 5A), and hence were utilized to find whether the cytotoxic activity of 1,4-naphthoquinone on cancer cells can be selectively influenced by the variation in IRAK1 expression in cells. IRAK1's RNA was hardly detected in A549 cells and thus was used as a control for relative expression comparison. U87 and PANC-1 cells had nearly equal expression of IRAK1's RNA and showed a 5-fold higher IRAK1 expression relative to A549 cells (Figure 5A). The relative expression of IRAK1's RNA in MCF-7 was 2-fold higher compared to that of A549 cells (Figure 5A). Notably, 1,4napthoquinone exerted high toxicity $\left(\mathrm{IC}_{50}<10 \mu \mathrm{M}\right)$ on cells overexpressing IRAK1 (Figure 5B). In fact, the drug showed the highest cytotoxicity (lowest $\mathrm{IC}_{50}$ ) on PANC-1 cells, which is nicely correlated with high expression of IRAK1 in these cells, compared to other cancer cell lines MCF-7 and U87 that showed higher $\mathrm{IC}_{50}$ values (Figure 5B). Interestingly, 1,4-napthoquinone demonstrated the lowest activity on A549 cells, which is correlated with the low expression of IRAK1 (Figure 5B), indicating the possible selectivity in action of 1,4-napthoquinone against IRAK1-overexpressing cells.

These findings indicate that the cytotoxicity of 1,4naphthoquinone on cancer cells could be significantly influenced by levels of IRAK1 in cancer cells. Having said that, the presence of other altered IRAK1-independent signaling pathways is highly possible in cancer cells and that may explain why some cells of high IRAK1 expression, such as U87 cells, may still have higher $\mathrm{IC}_{50}$ values than cells of lower IRAK1 expression, such as MCF-7 (Figure 5).

Measuring the Effect of 1,4-Naphthoquinone on the Production and Secretion of Proinflammatory Cyto- 


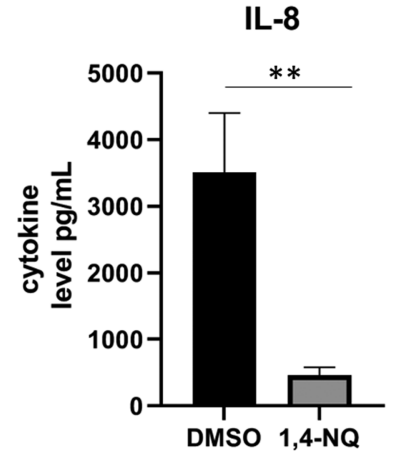

IL-6

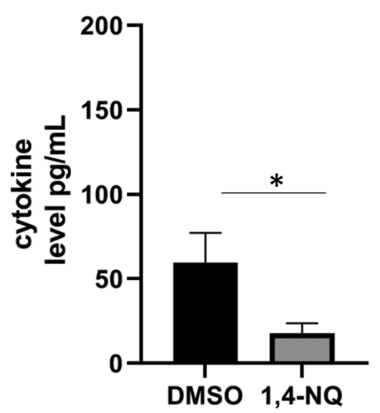

TNF- $\alpha$

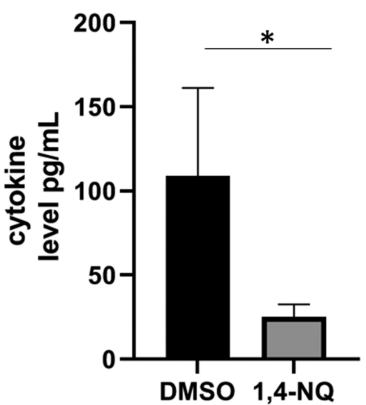

IL-10

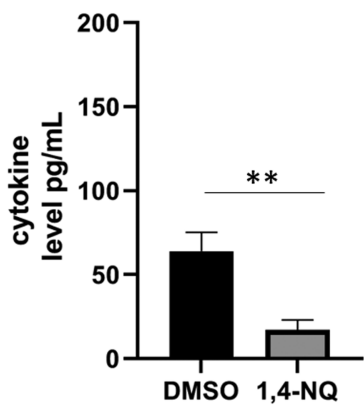

IL-1 $\beta$

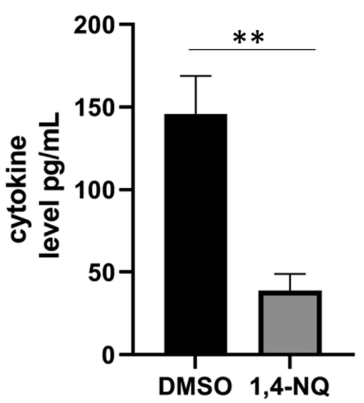

IL-12p70

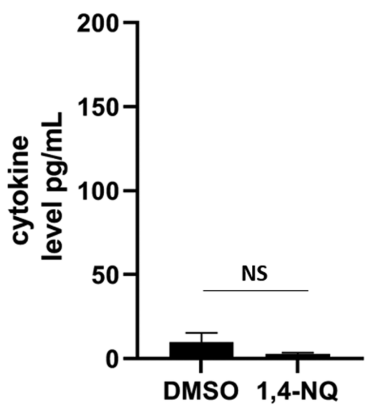

Figure 6. Effect of 1,4-napthoquinone on the production of cytokines in LPS-stimulated PMA-induced human THP-1 macrophages. The effect of 1,4naphthoquinone on the production of inflammatory cytokines in LPS-stimulated THP-1-induced macrophages was assessed in vitro using human inflammatory cytokines CBA array beads analyzed by flow cytometry. Quantification of released cytokines (IL-8, TNF- $\alpha$, IL-1 $\beta$, IL-6, IL-10, and IL12p70) was determined in $\mathrm{pg} / \mathrm{ml}$ in the culture medium after treating the cells with $1 \mu \mathrm{M}$ 1,4-naphthoquinone in comparison to control cells treated with DMSO. Data are expressed as mean \pm SD. $P$-value was calculated using $t$-test. $* p<0.05$. $* * p<0.01$. $* * *<0.001$. NS (not significant).

kines. To further assess the ability of 1,4-napthoquinone to inhibit the inflammatory response in immune cells and subsequent production and secretion of proinflammatory cytokines, the LPS-stimulated PMA-induced human THP-1 macrophages were treated with 1,4-naphthoquinone and the supernatant was harvested and analyzed for the key proinflammatory cytokines: IL- $1 \beta$, TNF- $\alpha$, IL- 10 , IL-6, IL- 8 , and IL$12 \beta$ using the FACS technique. The results showed a significant decrease $(p$-value $<0.05)$ in the levels of most of measured cytokines after treatment with 1,4-naphthoquinone compared to control DMSO (Figure 6). Notably, IL-8, IL-1 $\beta$, and IL-10 were the most downregulated ( $p$-value $<0.01$ ) as demonstrated by statistical significance levels (Figure 6).

IL-8 is a chemoattractant cytokine produced by various types of tissues and blood cells, where it primarily attracts and activates neutrophils in inflammatory regions. ${ }^{37}$ Interestingly, Bhaumik et al. have demonstrated that upregulation of miRNA-146a/b resulted in the downregulation of IRAK1 and subsequent inhibition of IL- 8 and IL- $6,{ }^{38}$ which indicates a direct role of IRAK1 in the regulation of IL- 8 cytokine. On the other hand, IL$1 \beta$ is a well-characterized proinflammatory cytokine that plays an important role in mediating host-defense response to infections. ${ }^{39}$ However, overproduction of IL- $1 \beta$ has been implicated in pathophysiological changes that occur during different diseases, such as rheumatoid arthritis, inflammatory bowel disease, osteoarthritis, multiple sclerosis, and Alzheimer's disease. $^{40}$ IL-10, formerly known as cytokine synthesis inhibitory factor, is considered as a key immunoregulatory cytokine. ${ }^{41}$ The cytokine has been associated with the deactivation of macrophages and dendritic cells and the subsequent production of proinflammatory cytokines such as IL-1, TNF- $\alpha$, and IL-12 from these cells. ${ }^{41}$ In contrast, other studies have shown that IL-10 is capable of exerting proinflammatory effects, indicating that IL-10 stimulates rather than inhibits inflammation. ${ }^{42,43}$

The range of biological effects of 1,4-naphthoquinones is diverse and includes antimicrobial, antitumor, and antiinflammatory activities. ${ }^{19,20,44-46}$ Very recently, Liu and his colleagues have shown that the 1,4-napthoquinone-derived compound (6-[1-(acetyloxy)ethyl]-5-hydroxy-2,7-dimethoxy1,4-naphthalenedione) was capable of reducing the RNA expression of proinflammatory cytokines IL1 $\beta$, IL-6, and TNF- $\alpha$ in LPS-induced murine macrophage cell line (RAW 264.7 cells). ${ }^{45}$ In the current study, we have utilized THP-1 monocytic cells to study the potential anti-inflammatory effect of 1,4-naphthoquinione on immune cells in vitro. The THP-1 cells can be differentiated into macrophages using Phorbol 12myristate 13-acetate (PMA) and has been widely utilized as a reliable in vitro system for studying immune cell processes. ${ }^{47}$ Also, it has been previously demonstrated that LPS could induce TNF- $\alpha$ expression by activating NF- $\kappa \mathrm{B}$ via the PI3K/AKT pathway, which is in turn dependent on IRAK1 enzyme. ${ }^{48}$ In the current study, our results reveal the ability of 1,4-napthoquinone to effectively inhibit the production of key proinflammatory cytokines, including IL-8, TNF- $\alpha$, IL-6, IL- $1 \beta$, and IL-10.

\section{CONCLUSIONS}

IRAK1 protein is a key signaling intermediate in the IL1R/TLR downstream cascade that leads to activation of several transcription factors, including NF- $\kappa \mathrm{B}$ and $\mathrm{AP}-1$, which 
contributes to the regulation of immune responses, inflammation, and apoptosis..$^{6}$ Indeed, our current findings support the notion that IRAK1-mediated signaling is a key component of the regulatory pathways that have direct and determining roles in inflammation.

Given the strong data indicating that IRAK1 enzyme is a critical regulator of inflammation, there has been considerable interest in developing anti-IRAK1-targeted drugs to treat inflammatory and autoimmune diseases. Naphthoquinones are a diverse group of natural products that are widely distributed on earth as common metabolites of plants, animals, fungi, and bacteria. $^{20}$ In fact, 1,4-naphthoquinone forms the central chemical structure of many natural compounds that have significant pharmacological properties, including $\mathrm{K}$ vitamins, juglone, plumbagin, shikonin, and lapachol. Our study shows the efficacy of napthoquinone-derived compounds, in particular 1,4naphthoquinone, in inhibiting the activity of IRAK1 enzymes, and suggests an unprecedented mechanism by which the 1,4napthoquinone agent exerts its anti-inflammatory action by suppressing the IRAK1 enzyme and subsequent production of important proinflammatory cytokines, such as IL-8, IL-6, IL-1 $\beta$, TNF- $\alpha$, and IL-10. Also, it opens a new window for researchers to enhance the activity of these compounds to exploit their potential in inhibiting IRAK1 enzyme to the maximum, as well as discover new IRAK1 inhibitors based on structure-activity relationships (SARs) in the future.

On the other hand, although there are some studies that may include quinones among pan-assay interference compounds (PAINS), ${ }^{49,50}$ we have demonstrated using in silico docking techniques that 1,4-napthoquinone compounds inhibit IRAK1 by fitting into a binding site within the protein. However, further wide kinase profiling of the compounds is needed to assess target specificity. Hence, reaching a balance between potential compound promiscuity and target specificity will likely be an important task for future drug application of 1,4-napthoquinone compounds.

\section{EXPERIMENTAL SECTION}

Chemicals, Reagents, and Cell Lines. The IRAK-1/4 inhibitor (\#MFCD09752602), 1,4-benzoquinone, thymoquinone, hydroquinone, juglone, phylloquinone (vitamin $\mathrm{K} 1$ ), menaquinone (vitamin K2), menadione (vitamin K3), 1,4naphthoquinone, shikonin, and lapachol were obtained from Sigma. Plumbagin (TCI, Japan), emodin (ABCR, Germany), TB Green Premix Ex Taq II (Takara Bio, Inc.), and human inflammatory cytokines CBA array beads for FACS detection and quantitation of inflammatory cytokines were obtained from BD (Biosciences). Lipopolysaccharide (LPS, Santa Cruz), phorbol 12-myristate 13-acetate (PMA, Biotechne), colorimetric Cell Titer 96 non-Radioactive Cell Proliferation Assay (Promega, Madison), human monocytic cell line (THP-1), breast cancer cell line (MCF-7), glioblastoma cell line (U87), pancreatic cancer cell line (PANC-1), and lung alveolar basal epithelial cells (A549) were obtained from (ATCC).

Oligos for QPCR. Oligos used in QPCR were purchased from Gene Link. The sequences of oligos used were as follows: IRAK1: FP; 5'-TCAGCTTTGGGGTGGTAGTG-3'; RP; 5'TAGATCTGCATGGCGATGGG-3'. 18S-rRNA: FP; $5^{\prime}$ CGAACGTCTGCCCTATCAACTT-3'; RP; 5'-ACCCGTGGTCACCATGGTA-3'.

Biochemical In Vitro Kinase Assays and IC C $_{50}$ Determination. All quinone compounds were dissolved in DMSO to prepare a stock solution of $10 \mathrm{mM}$ and stored in a fridge. The
IRAK1 and IRAK4 kinase assays were performed using fluorescence resonance energy transfer (FRET)-based Adapta and ZLYTE Kinase assay kits, subsequently (SelectScreen service, Thermo Fisher Scientific). ATP $(10 \mu \mathrm{M})$ was used in all reactions. For initial screening, a single concentration of each compound at $10 \mu \mathrm{M}$ was tested against IRAK1 and IRAK4 (Table 1). For $\mathrm{IC}_{50}$ determination, serial dilutions of selected compounds were prepared in DMSO (Figure 2) and the $\mathrm{IC}_{50}$ value was calculated using the nonlinear regression (variable slope, four parameters) of the log concentration as inhibition percentage values using GraphPad Prism 9.0.

Cell Cytotoxicity Assay. The human cancer cell lines MCF7, U87, PANC-1, and A549 were all subjected to 3-(4,5dimethylthiazol-2-yl)-2,5-diphenyltetrazolium bromide (MTT) cytotoxicity assay. Briefly, the cells were seeded at a density of 5 $\times 10^{3}$ per well in 96-well plates in appropriate medium and then treated with increasing concentration of each compound (0.2$100 \mu \mathrm{mol} / \mathrm{L})$. Colorimetric Cell Titer 96 non-Radioactive Cell Proliferation Assay (Promega, Madison) was used to detect cell proliferation in each well according to manufacturer's instructions.

Cell Culture and Production of THP-1 Differentiated Macrophages. The human monocytic cell line THP-1 was maintained in cell culture growth medium; RPMI 1640 medium (Euroclone) supplemented with $2 \mathrm{mM}$ L-glutamine, $100 \mathrm{mg} / \mathrm{mL}$ penicillin/streptomycin (Gibco), $4.5 \mathrm{~g} / \mathrm{L}$ D-glucose (Sigma), and $20 \%$ fetal bovine serum (Euroclone). For the induction of cell differentiation into macrophages, THP-1 cells were resuspended to a concentration of $2 \times 10^{5}$ cells per $\mathrm{mL}$ in a fresh RPMI medium supplemented with $100 \mathrm{nM}$ PMA, and then distributed in a 24-well plate (SPL, Korea) at a density of $1 \mathrm{~mL}$ per well for $24 \mathrm{~h}$. After incubation, nonattached cells were removed by aspiration and the adherent cells were maintained in RPMI cell culture medium. For cell stimulation, the adherent macrophages were further treated with $5 \mu \mathrm{g} / \mathrm{mL}$ lipopolysaccharide (LPS) prepared in fresh culture medium RPMI and incubated for further $24 \mathrm{~h}$. After $24 \mathrm{~h}$ of stimulation, the obtained cells were grown in RPMI medium supplemented with $1 \mu \mathrm{M} \mathrm{1,4-naphthoquinone,} \mathrm{in} \mathrm{addition} \mathrm{to} \mathrm{the} \mathrm{internal} \mathrm{control}$ DMSO, for $24 \mathrm{~h}$. Untreated cells were used as negative control.

Measurement of the RNA Expression of IRAK1 by QPCR. To measure the RNA expression of IRAK1 in different cancer cell lines, $\sim 1 \times 10^{6}$ cells of each cell line were harvested and RNA was extracted and then quantified using the QPCR method. The extracted RNA was quantified by a NanoDrop (Thermo Fisher Scientific). To synthesize cDNA, $0.5 \mu \mathrm{g}$ of total RNA was reverse transcribed using the PrimeScript RT Master Mix (Takara, Dalina, China) using a T100 Thermal Cycler PCR instrument (Bio-Rad). The Q-PCR reaction mix was prepared by mixing $2 \mu \mathrm{L}$ of cDNA with $0.4 \mu \mathrm{L}$ of forward primer, $0.4 \mu \mathrm{L}$ of reverse primer, $7.2 \mu \mathrm{L}$ of free nuclease water, and $10 \mu \mathrm{L}$ of SYBRPremixEx2 (TliPlus) (Takara Bio). Q-PCR was performed using a CFX96 C1000 Touch thermal cycler (Bio-Rad, Hercules, CA) with the following temperature setting: (i) $95^{\circ} \mathrm{C}$ for $3 \mathrm{~min}$ and (ii) $40 \mathrm{cycles}$ at $95^{\circ} \mathrm{C}$ for $5 \mathrm{~s}$ and at $61^{\circ} \mathrm{C}$ for $30 \mathrm{~s}$. 18S-rRNA was used as a reference gene. Each sample was examined in triplicate, and a mean value was calculated. Data were analyzed according to the $2^{-\Delta \Delta C T}$ method using CFX Maestro Software (Bio-Rad).

Cytometric Beads Array (CBA) for Human Inflammatory Cytokines and FACS Analysis. To evaluate the impact of 1,4-naphthoquinone on the production and secretion of inflammatory cytokines in THP-1-induced macrophages, a 
panel of cytokine proteins (IL- $1 \beta$, TNF- $\alpha$, IL-6, IL-8, IL-10, and IL-12p70) were detected and quantified by human inflammatory cytokine CBA array beads (BD, Biosciences) using the flow cytometry technique. For the quantification of released cytokines (IL- $1 \beta$, TNF- $\alpha$, IL-6, IL-8, IL-10, and IL-12p70), the culture medium (supernatants) was collected after treating the cells with 1,4-naphthoquinone, in addition to the internal control DMSO and then kept at $-80{ }^{\circ} \mathrm{C}$ until further analysis. Supernatants were thawed and analyzed with the multiplex cytokine detection systems CBA array human inflammatory cytokines (BD, Biosciences). The samples were prepared in triplicate and analyzed according to manufacturer's instructions. All standards and samples were acquired and analyzed on FACS Canto II (BD, Biosciences). The cytokine standard curves are included in the supplementary data (Figure S1). The final concentration of cytokines in each sample was calculated according to the following equation

$$
C_{\text {final }}=\frac{C_{\text {standard }} \times V_{\text {sample }} \times \text { dilution factor }}{N_{\text {cells }}}
$$

where $C_{\text {final }}$ is the final concentration (in $\mathrm{pg} / \mathrm{mL}$ ), $C_{\text {standard }}$ is the concentration derived from the standard curves (in $\mathrm{pg} / \mathrm{mL}$ ), $V_{\text {sample }}$ is the sample volume, and $N_{\text {cells }}$ is the number of analyzed cells.

Molecular Interactions and Docking Analysis. The docking study was carried out using the collected set of inhibitors into the proposed binding pocket of the X-ray crystallographic structure (PDB ID: 6BFN, resolution: $2.26 \AA$ ). Docking was carried out using docking engine CDOCKER. ${ }^{51}$ The binding pocket was defined as the cavity volume occupied by $\mathrm{DL} 1$ ligand $\left(\mathrm{IC}_{50}: 9.3 \mathrm{nM}\right)$ in the X-ray structure. ${ }^{34}$ CDOCKER is a CHARMm-based simulated annealing/ molecular dynamics method that uses rigid receptor for docking. CDOCKER protocol includes the following steps: (i) A set of ligand conformations are generated using high-temperature molecular dynamics starting with different random seeds. (ii) Random orientations of the conformations are produced by translating the center of the ligand to a specified location within the receptor catalytic site and performing a series of random rotations. (iii) A softened energy is calculated and the orientation is kept if the energy is less than a specified threshold. This continues until either the desired number of low-energy orientations is found or the maximum number of bad orientations has been tried. (iv) Each orientation is subjected to simulated annealing molecular dynamics. The temperature is increased to a high value and then decreased to the target temperature. (v) A final minimization of the ligand in the rigid receptor using nonsoftened potential is performed. For each final pose, the CHARMm energy (interaction energy plus ligand strain) and the interaction energy alone are calculated. The poses are sorted by CHARMm energy and the top scoring (most negative, thus favorable to binding) poses are retained. The following CDOCKER parameters were implemented in the presented study: A binding site sphere of $8.1 \AA$ radius surrounding the center of the co-crystallized ligand (PDB ID: $6 \mathrm{BFN})$ was implemented. Starting ligands' conformers were energy-minimized and then heated to $1000 \mathrm{~K}$ over 1000 molecular dynamics steps to generate 10 starting random conformations for each ligand. Each random conformer was rotated 10 times within the binding pocket for subsequent energy refinement. The van der Waals energies of the resulting conformers/poses were evaluated, and those of $\geq 300 \mathrm{kcal} / \mathrm{mol}$ were discarded. Surviving conformers/poses were exposed to a cycle of simulated annealing over 2000 heating steps to the targeted temperature of $700 \mathrm{~K}$ followed by 5000 cooling steps to the targeted temperature of $300 \mathrm{~K}$. The docked poses were energy-minimized to a final minimization gradient tolerance of 0 $\mathrm{kcal} / \mathrm{mol} / \AA^{52}$ Top 10 poses were saved, and the top structure was further minimized 10 steps before performing contact analysis. ${ }^{53,54}$ Discovery Studio Visualizer V20.1.0.19295 (Dassault Systems BIOVIA, 2019 copyright) was used to study the interactions between molecules.

Statistical Analysis. Statistical analysis was performed using GraphPad Prism 9.0. The $t$-test was used to measure significance of the data. $P$-values $<0.05$ were considered statistically significant, $* * * P<0.001$. ${ }^{* *} P<0.01$. $* P<0.05$.

\section{ASSOCIATED CONTENT}

\section{Supporting Information}

The Supporting Information is available free of charge at https://pubs.acs.org/doi/10.1021/acsomega.1c03081.

Standard curves for the CBA array human inflammatory cytokines panel (PDF)

\section{AUTHOR INFORMATION}

\section{Corresponding Authors}

Ismail Sami Mahmoud - Department of Medical Laboratory Sciences, Faculty of Applied Medical Sciences, The Hashemite University, Zarqa 13133, Jordan; 이이.org/0000-00026210-9832; Phone: 00962797545880; Email: ismails@ hu.edu.jo

Walhan Alshaer - Cell Therapy Centre, The University of Jordan, Amman 11942, Jordan; 이이.org/0000-00032946-7328; Phone: 00962790823678;

Email: walhan.alshaer@ju.edu.jo

\section{Authors}

Ma'mon M. Hatmal - Department of Medical Laboratory Sciences, Faculty of Applied Medical Sciences, The Hashemite University, Zarqa 13133, Jordan

Duaa Abuarqoub - Cell Therapy Centre, The University of Jordan, Amman 11942, Jordan; Department of Pharmacology and Biomedical Sciences, Faculty of Pharmacy and Medical Sciences, University of Petra, Amman 11180, Jordan

Ezaldeen Esawi - Cell Therapy Centre, The University of Jordan, Amman 11942, Jordan; Department of Pathology and Laboratory Medicine, King Hussein Cancer Center, Amman 11941, Jordan

Hiba Zalloum - Hamdi Mango Centre for Scientific Research, The University of Jordan, Amman 11942, Jordan

Suha Wehaibi - Cell Therapy Centre, The University of Jordan, Amman 11942, Jordan

Hamdi Nsairat - Pharmacological and Diagnostic Research Centre, Faculty of Pharmacy, Al-Ahliyya Amman University, Amman 19328, Jordan; (1) orcid.org/0000-0001-5916-5879

Complete contact information is available at:

https://pubs.acs.org/10.1021/acsomega.1c03081

\section{Author Contributions}

I.S.M. contributed to the conception, designing, supervision, data analysis, and writing of the manuscript. M.M.H. was involved in methodology (molecular simulations and docking analysis) and revising of the manuscript. D.A. was involved in methodology (involved in inflammatory cytokines analysis) and 
revising of the manuscript. E.E. contributed to methodology (involved in cytotoxicity assays) and revising of the manuscript. S.W. was involved in methodology (QPCR assays) and revising of the manuscript. H.N. revised the manuscript. H.Z. contributed to methodology (involved in docking) and revising of the manuscript. W.A. performed supervision and revising of the manuscript.

\section{Funding}

This work was supported by funding from the Hashemite University, Jordan. Grant number: (88-2019).

\section{Notes}

The authors declare no competing financial interest.

\section{ACKNOWLEDGMENTS}

The authors gratefully acknowledge the Cell Therapy Centre, The University of Jordan, for technical support.

\section{ABBREVIATIONS USED}

MyD88, myeloid differentiation primary response 88; AP-1, activator protein-1; NF- $\kappa \mathrm{B}$, nuclear factor kappa B; TRAF6, TNFR-associated factor 6; INF, interferon; TNF, tumor necrosis factor; IL, interleukin; FRET, fluorescence resonance energy transfer; FACS, fluorescence-activated cell sorting; CHARMm, chemistry at Harvard Macromolecular mechanics; DMSO, dimethyl sulfoxide; rRNA, ribosomal RNA; QPCR, quantitative polymerase chain reaction; IC50, half-maximal inhibitory concentration

\section{REFERENCES}

(1) Loiarro, M.; Ruggiero, V.; Sette, C. Targeting TLR/IL-1R signalling in human diseases. Mediators Inflammation 2010, 2010, No. 674363.

(2) Kawai, T.; Akira, S. The role of pattern-recognition receptors in innate immunity: update on Toll-like receptors. Nat. Immunol. 2010, 5 , 373-384.

(3) Gottipati, S.; Rao, N. L.; Fung-Leung, W. P. IRAK1: a critical signaling mediator of innate immunity. Cell. Signal. 2008, 20, 269-276.

(4) Cao, Z.; Henzel, W. J.; Gao, X. IRAK: a kinase associated with the interleukin-1 receptor. Science 1996, 271, 1128-1131.

(5) Rhyasen, G. W.; Starczynowski, D. T. IRAK signalling in cancer. Br. J. Cancer. 2015, 112, 232-237.

(6) Jain, A.; Kaczanowska, S.; Davila, E. IL-1 Receptor-Associated Kinase Signaling and Its Role in Inflammation, Cancer Progression, and Therapy Resistance. Front. Immunol. 2014, 5, 553.

(7) Zhang, G.; Ghosh, S. Toll-like receptor-mediated NF-kappaB activation: a phylogenetically conserved paradigm in innate immunity. J. Clin. Invest. 2001, 107, 13-19.

(8) Wang, Z.; Wesche, H.; Stevens, T.; Walker, N.; Yeh, W. C. IRAK-4 inhibitors for inflammation. Curr. Top. Med. Chem. 2009, 9, 724-737.

(9) Singer, J. W.; Fleischman, A.; Al-Fayoumi, S.; Mascarenhas, J. O.; Yu, Q.; Agarwal, A. Inhibition of interleukin-1 receptor-associated kinase 1 (IRAK1) as a therapeutic strategy. Oncotarget. 2018, 9, 3341633439.

(10) Cushing, L.; Winkler, A.; Jelinsky, S. A.; Lee, K.; Korver, W.; Hawtin, R.; Rao, V. R.; Fleming, M.; Lin, L. L. IRAK4 kinase activity controls Toll-like receptor-induced inflammation through the transcription factor IRF5 in primary human monocytes. J. Biol. Chem. 2017, 292, 18689-18698.

(11) Yuan, B.; Shen, H.; Lin, L.; Su, T.; Zhong, L.; Yang, Z. MicroRNA367 negatively regulates the inflammatory response of microglia by targeting IRAK4 in intracerebral hemorrhage. J. Neuroinflammation 2015, 12, No. 206.

(12) Ahmad, R.; Shihab, P. K.; Thomas, R.; Alghanim, M.; Hasan, A.; Sindhu, S.; Behbehani, K. Increased expression of the interleukin-1 receptor-associated kinase (IRAK)-1 is associated with adipose tissue inflammatory state in obesity. Diabetol. Metab. Syndr. 2015, 7, No. 71.

(13) Singh, N.; Li, L. Reduced oxidative tissue damage during endotoxemia in IRAK-1 deficient mice. Mol. Immunol. 2012, 50, 244252.

(14) Chandra, R.; Federici, S.; Bishwas, T.; Németh, Z. H.; Deitch, E. A.; Thomas, J. A.; Spolarics, Z. IRAK1-dependent signaling mediates mortality in polymicrobial sepsis. Inflammation 2013, 36, 1503-1512.

(15) Son, E. J.; Kim, J. H.; Kim, K.; Park, C. B. Quinone and its derivatives for energy harvesting and storage materials. J. Mater. Chem. A 2016, 4, 11179-11202.

(16) El-Najjar, N.; Gali-Muhtasib, H.; Ketola, R. A.; Vuorela, P.; Urtti, A.; Vuorela, H. The chemical and biological activities of quinones: overview and implications in analytical detection. Phytochem. Rev. 2011, 10, No. 353.

(17) Hossen, M. J.; Yang, W. S.; Kim, D.; Aravinthan, A.; Kim, J. H.; Cho, J. Y. Thymoquinone: An IRAK1 inhibitor with in vivo and in vitro anti-inflammatory activities. Sci. Rep. 2017, 7, No. 42995.

(18) Imran, M.; Rauf, A.; Khan, I. A.; Shahbaz, M.; Qaisrani, T. B.; Fatmawati, S.; Abu-Izneid, T.; Imran, A.; Rahman, K. U.; Gondal, T. A. Thymoquinone: A novel strategy to combat cancer: A review. Biomed. Pharmacother. 2018, 106, 390-402.

(19) Kayashima, T.; Mori, M.; Yoshida, H.; Mizushina, Y.; Matsubara, K. 1,4-Naphthoquinone is a potent inhibitor of human cancer cell growth and angiogenesis. Cancer Lett. 2009, 278, 34-40.

(20) Aminin, D.; Polonik, S. 1,4-Naphthoquinones: Some Biological Properties and Application. Chem. Pharm. Bull. 2020, 68, 46-57.

(21) Han, J. W.; Shim, D. W.; Shin, W. Y.; Heo, K. H.; Kwak, S. B.; Sim, E. J.; Jeong, J. H.; Kang, T. B.; Lee, K. H. Anti-inflammatory effect of emodin via attenuation of NLRP3 inflammasome activation. Int. J. Mol. Sci. 2015, 16, 8102-8109.

(22) Wei, W. T.; Lin, S. Z.; Liu, D. L.; Wang, Z. H. The distinct mechanisms of the antitumor activity of emodin in different types of cancer (Review). Oncol. Rep. 2013, 30, 2555-2562.

(23) Peres, R. S.; Santos, G. B.; Cecilio, N. T.; Jabor, V. A.; Niehues, M.; Torres, B. G.; Buqui, G.; Silva, C. H.; Costa, T. D.; Lopes, N. P.; Nonato, M. C.; Ramalho, F. S.; Louzada-Júnior, P.; Cunha, T. M.; Cunha, F. Q.; Emery, F. S.; Alves-Filho, J. C. Lapachol, a compound targeting pyrimidine metabolism, ameliorates experimental autoimmune arthritis. Arthritis Res Ther. 2017, No. 47.

(24) Epifano, F.; Genovese, S.; Fiorito, S.; Mathieu, V.; Kiss, R. Lapachol and its congeners as anticancer agents: A review. Phytochem. Rev. 2014, 13, 37-49.

(25) Luo, P.; Wong, Y. F.; Ge, L.; Zhang, Z. F.; Liu, Y.; Liu, L.; Zhou, $\mathrm{H}$. Anti-inflammatory and analgesic effect of plumbagin through inhibition of nuclear factor- $\kappa \mathrm{B}$ activation. J. Pharmacol. Exp. Ther. 2010, $335,735-742$.

(26) Cao, Y. Y.; Yu, J.; Liu, T. T.; Yang, K. X.; Yang, L. Y.; Chen, Q.; Shi, F.; Hao, J. J.; Cai, Y.; Wang, M. R.; Lu, W. H.; Zhang, Y. Plumbagin inhibits the proliferation and survival of esophageal cancer cells by blocking STAT3-PLK1-AKT signaling. Cell Death Dis. 2018, 9, No. 17.

(27) Seetha, A.; Devaraj, H.; Sudhandiran, G. Indomethacin and juglone inhibit inflammatory molecules to induce apoptosis in colon cancer cells. J. Biochem. Mol. Toxicol. 2020, 34, No. e22433.

(28) Liao, P. L.; Lin, C. H.; Li, C. H.; Tsai, C. H.; Ho, J. D.; Chiou, G. C.; Kang, J. J.; Cheng, Y. W. Anti-inflammatory properties of shikonin contribute to improved early-stage diabetic retinopathy. Sci Rep. 2017, 7, No. 44985 .

(29) Lamson, D. W.; Plaza, S. M. The anticancer effects of vitamin K. Altern. Med. Rev. 2003, 8, 303-318.

(30) Ohsaki, Y.; Shirakawa, H.; Hiwatashi, K.; Furukawa, Y.; Mizutani, T.; Komai, M. Vitamin K suppresses lipopolysaccharide-induced inflammation in the rat. Biosci., Biotechnol., Biochem. 2006, 70, 926932.

(31) Hatcher, J. M.; Yang, G.; Wang, L.; Ficarro, S. B.; Buhrlage, S.; Wu, H.; Marto, J. A.; Treon, S. P.; Gray, N. S. Discovery of a Selective, Covalent IRAK1 Inhibitor with Antiproliferative Activity in MYD88 Mutated B-Cell Lymphoma. ACS Med. Chem. Lett. 2020, 11, 22382243. 
(32) Isnardi, I.; Ng, Y. S.; Srdanovic, I.; Motaghedi, R.; Rudchenko, S.; von Bernuth, H.; Zhang, S. Y.; Puel, A.; Jouanguy, E.; Picard, C.; Garty, B. Z.; Camcioglu, Y.; Doffinger, R.; Kumararatne, D.; Davies, G.; Gallin, J. I.; Haraguchi, S.; Day, N. K.; Casanova, J. L.; Meffre, E. IRAK-4- and MyD88-dependent pathways are essential for the removal of developing autoreactive B cells in humans. Immunity 2008, 29, 746757.

(33) Pattabiraman, G.; Murphy, M.; Agliano, F.; Karlinsey, K.; Medvedev, A. E. IRAK4 activity controls immune responses to intracellular bacteria Listeria monocytogenes and Mycobacterium smegmatis. J. Leukoc. Biol. 2018, 104, 811-820.

(34) Hu, Y.; Stumpfe, D.; Bajorath, J. Advancing the activity cliff concept. F1000Res. 2013, 2013, No. 199.

(35) González-Bello, C. Designing Irreversible Inhibitors-Worth the Effort? ChemMedChem. 2016, 11, 22-30.

(36) Wang, L.; Qiao, Q.; Ferrao, R.; Shen, C.; Hatcher, J. M.; Buhrlage, S. J.; Gray, N. S.; Wu, H. Crystal structure of human IRAK1. Proc. Natl. Acad. Sci. U.S.A. 2017, 114, 13507-13512.

(37) Bickel, M. The role of interleukin-8 in inflammation and mechanisms of regulation. J Periodontol. 1993, 64, 456-460.

(38) Bhaumik, D.; Scott, G. K.; Schokrpur, S.; Patil, C. K.; Orjalo, A. V.; Rodier, F.; Lithgow, G. J.; Campisi, J. MicroRNAs miR-146a/b negatively modulate the senescence-associated inflammatory mediators IL-6 and IL-8. Aging 2009, 1, 402-411.

(39) Lopez-Castejon, G.; Brough, D. Understanding the mechanism of IL-1 $\beta$ secretion. Cytokine Growth Factor Rev. 2011, 22, 189-195.

(40) Ren, K.; Torres, R. Role of interleukin-lbeta during pain and inflammation. Brain Res. Rev. 2009, 60, 57-64.

(41) Mühl, H. Pro-Inflammatory Signaling by IL-10 and IL-22: Bad Habit Stirred Up by Interferons? Front. Immunol. 2013, 4, 18.

(42) Tilg, H.; van Montfrans, C.; van den Ende, A.; Kaser, A.; van Deventer, S. J.; Schreiber, S.; Gregor, M.; Ludwiczek, O.; Rutgeerts, P.; Gasche, C.; Koningsberger, J. C.; Abreu, L.; Kuhn, I.; Cohard, M.; LeBeaut, A.; Grint, P.; Weiss, G. Treatment of Crohn's disease with recombinant human interleukin 10 induces the proinflammatory cytokine interferon gamma. Gut 2002, 50, 191-195.

(43) Lauw, F. N.; Pajkrt, D.; Hack, C. E.; Kurimoto, M.; van Deventer, S. J.; van der Poll, T. Proinflammatory effects of IL-10 during human endotoxemia. J. Immunol. 2000, 156, 2783-2789.

(44) Riffel, A.; Medina, L. F.; Stefani, V.; Santos, R. C.; Bizani, D.; Brandelli, A. In vitro antimicrobial activity of a new series of 1,4naphthoquinones. Braz. J. Med. Biol. Res. 2002, 35, 811-818.

(45) Liu, H.; Yan, C.; Li, C.; You, T.; She, Z. Naphthoquinone Derivatives with Anti-Inflammatory Activity from Mangrove-Derived Endophytic Fungus Talaromyces sp. SK-S009. Molecules 2020, 25, No. 576.

(46) Pereyra, C. E.; Dantas, R. F.; Ferreira, S. B.; Gomes, L. P.; Silva-Jr, F. P. The diverse mechanisms and anticancer potential of naphthoquinones. Cancer Cell Int. 2019, 19, No. 207.

(47) Chanput, W.; Mes, J. J.; Wichers, H.J. THP-1 cell line: an in vitro cell model for immune modulation approach. Int. Immunopharmacol. 2014, 23, 37-45.

(48) Park, S. H.; Choi, H.-J.; Lee, S. Y.; Han, J.-S. TLR4-mediated IRAK1 activation induces TNF- $\alpha$ expression via JNK-dependent NF$\kappa \mathrm{B}$ activation in human bronchial epithelial cells. Eur. J. Inflammation 2015, 13, 183-195.

(49) Baell, Jonathan B.; Ferrins, Lori.; Falk, Hendrik.; Nikolakopoulos, George. PAINS: Relevance to Tool Compound Discovery and Fragment-Based Screening. Aust. J. Chem. 2013, 66, 1483-1494.

(50) Baell, J.; Walters, M. A. Chemistry: Chemical con artists foil drug discovery. Nature 2014, 503, 481-483.

(51) Wu, G.; Robertson, D. H.; Brooks, C. L., 3rd; Vieth, M. Detailed analysis of grid-based molecular docking: A case study of CDOCKER-A CHARMm-based MD docking algorithm. J. Comput. Chem. 2003, 24, $1549-1562$.

(52) Baloji, G.; Pasham, S.; Mahankali, V.; Garladinne, M.; Ankanagari, S. Insights from the molecular docking analysis of phytohormone reveal brassinolide interaction with HSC70 from Pennisetum glaucum. Bioinformation 2019, 2, 131-138.

(53) Hatmal, M. M.; Taha, M. O. Simulated annealing molecular dynamics and ligand-receptor contacts analysis for pharmacophore modeling. Future Med. Chem. 2017, 9, 1141-1159.

(54) Hatmal, M. M.; Jaber, S.; Taha, M. O. Combining molecular dynamics simulation and ligand-receptor contacts analysis as a new approach for pharmacophore modeling: beta-secretase 1 and check point kinase 1 as case studies. J. Comput.-Aided Mol. Des. 2016, 30, $1149-1163$

\section{NOTE ADDED AFTER ASAP PUBLICATION}

This paper was published ASAP on September 17, 2021, with an error in the title. The corrected version was reposted on September 22, 2021. 